\title{
O gênero Isabelia (Orchidaceae: Laeliinae) no estado do Paraná, Brasil
} The genus Isabelia in Paraná state, Brazil

\author{
Mathias Erich Engels ${ }^{1,2}$ \& Rosângela Capuano Tardivo ${ }^{1}$
}

\begin{abstract}
Resumo
Isabelia Barb. Rodr. é endêmico da América do Sul, constituído por três espécies e um nototáxon. No Brasil, são encontrados todos os táxons, distribuídos nos domínios fitogeográficos do Cerrado e da Mata Atlântica, nas Regiões Sul, Sudeste, Centro-oeste e Nordeste. Um estudo taxonômico do gênero Isabelia foi realizado no Paraná e os resultados revelaram a ocorrência de todas as espécies descritas: Isabelia pulchella (Kraenzl.) Van den Berg \& M.W. Chase; Isabelia violacea (Lindl.) Van den Berg \& M.W. Chase, Isabelia virginalis Barb. Rodr. e do nototáxon Isabelia × pabstii (Leinig) Van den Berg \& M.W. Chase. São apresentadas chave de identificação, descrições morfológicas, mapa de distribuição geográfica, comentários, status de conservação e ilustrações dos táxons estudados.
\end{abstract}

Palavras-chave: América do Sul, flora do Paraná, nototáxon, taxonomia.

\begin{abstract}
Isabelia Barb. Rodr. is a South-american endemic genus, formed by three species and a nototaxon. All taxa are found in Brazil, distributed in the phytogeografic domain of the Cerrado and of the Atlantic Forest, in the South, Southeast, Center-west and in the Northeast regions. A taxonomic study of the Isabelia was presented in Paraná and the results revealed the occurrence of all the described species: Isabelia pulchella (Kraenzl.) Van den Berg \& M.W. Chase; Isabelia violacea (Lindl.) Van den Berg \& M.W. Chase, Isabelia virginalis Barb. Rodr. and the nototaxon Isabelia $\times$ pabstii (Leinig) Van den Berg \& M.W. Chase. Identification key, morphological descriptions, geographic distribution, comments, status of conservation and illustration are presented of each species.

Key words: South-America, flora of Paraná, nototaxon, taxonomic study.
\end{abstract}

\section{Introdução}

Orchidaceae A. Juss. ocorre em todo o globo, e é considerada uma das maiores entre as Angiospermas, sendo conhecidas 25.971 espécies, mas com estimativa de ca. 30.000 (Joppa et al. 2010). Para o Brasil são citados 236 gêneros e 2.432 espécies e para o estado do Paraná são citados 127 gêneros e 588 espécies (Barros et al. 2012). Embora seja encontrada em todos os biomas brasileiros, a Mata Atlântica é o que abriga a maior riqueza específica (Pabst \& Dungs 1975).

A etimologia do nome Isabelia é um tributo que João Barbosa Rodrigues paga a sua Alteza Imperial D. Isabel, Condessa d`Eu, como reconhecimento de ser protetora da ciência e floricultura (Rodrigues 1877).

Na sistemática atual, Isabelia Barb. Rodr. está enquadrada na subfamília Epidendroideae Lindley, com uma antera fértil, rostrada e incumbente, e a presença de polínias; na tribo Epidendreae Humb., Bonpl. \& Kunth por possuir polínias ceróides e desprovidas de estipe; e na Subtribo Laeliinae Benth. pelas polínias achatadas lateralmente. Juntamente com Constantia Barb. Rodr., Pseudolaelia Porto \& Brade, Loefgrenianthus Hoehne e Leptotes Lindl., Isabelia faz parte de um pequeno grupo basal em Laeliinae, constituído por aproximadamente 28 espécies. As características deste grupo são: pequenas flores em relação ao restante da subtribo, coluna curta em relação ao labelo e estigma bastante largo comparado com o comprimento da coluna (van den Berg et al. 2009). Os gêneros monoespecíficos Neolauchea Kraenzl., Sophronitella Schltr. e $\times$ Isanitella Leinig foram sinonimizados sob Isabelia, baseado em dados moleculares (van den Berg et al. 2000; van den Berg \& Chase 2001).

\footnotetext{
${ }^{1}$ Universidade Estadual de Ponta Grossa, Campus Uvaranas, Av. General Carlos Cavalcanti 4748, 84030-900, Ponta Grossa, PR.

${ }^{2}$ Autor para correspondência: mathiasengels@hotmail.com
} 
Isabelia é constituído por três espécies, $I$. pulchella (Kraenzl.) Van den Berg \& M.W.Chase; I. violacea (Lindl.) Van den Berg \& M.W. Chase, I. virginalis Barb. Rodr. e um nototáxon, Isabelia $\times$ pabstii (Leinig) Van den Berg \& M.W. Chase (Pabst \& Dungs 1975; Pridgeon et al. 2005; Govaerts 2011; Barros et al. 2012). Este último é um híbrido natural entre I. pulchella e I. violacea, coletado pela primeira vez por Leinig em 1969 nos arenitos do Parque Estadual de Vila Velha, Ponta Grossa, Paraná (Leinig 1971).

Isabelia é endêmico da América do Sul, ocorrendo nos domínios fitogeográficos da Mata Atlântica e do Cerrado, podendo ser encontrado no nordeste da Argentina (Misiones) e no Brasil, nas Regiões Sul (Paraná, Santa Catarina e Rio Grande do Sul), Sudeste (Minas Gerais, São Paulo e Rio de Janeiro), Centro-oeste (Goiás e Distrito Federal) e Nordeste (Bahia) (Govaerts 2011; Barros et al. 2012).

O presente trabalho trata do estudo florístico e taxonômico de Isabelia no estado do Paraná, com descrições, ilustrações, chave de identificação e dados de distribuição geográfica, bem como fornece dados do status de conservação dos táxons estudados.

\section{Material e Métodos}

Foram realizadas expedições nas unidades fitogeográficas do Paraná entre março de 2008 a outubro de 2011: Floresta Ombrófila Densa (Floresta Atlântica), Floresta Ombrófila Mista (Floresta com Araucária), Floresta Estacional Semidecidual Subxérica (Floresta Estacional), Estepe Ombrófila (Campos Gerais) e Savana Estacional Subxérica (Cerrado), classificadas de acordo com Veloso et al. (1991).

Os exemplares férteis foram coletados e herborizados segundo as técnicas usuais da taxonomia vegetal (Fidalgo \& Bononi 1989) e as exsicatas foram depositadas no Herbário da Universidade Estadual de Ponta Grossa (HUPG).

Além do material coletado, foram estudadas as coleções dos herbários EFC, HB, HUEM, HUPG, MBM, RB, SP, UPCB, cujos acrônimos estão de acordo com Thiers, na versão online do Index Herbariorum disponível em <http:// sweetgun.nybg.org/ih/>.

A terminologia morfológica adotada está de acordo com Vidal \& Vidal (1972) e Gonçalves \& Lorenzi (2011). Os nomes aceitos e sinônimos foram utilizados segundo Govaerts (2011) e Barros et al. (2012). O estado de conservação dos táxons foi baseado em critérios e categorias estabelecidos pela IUCN (2010), sendo também examinado a Lista Vermelha de Plantas Ameaçadas de Extinção no Estado do Paraná (Hatschbach \& Ziller 1995).

A descrição de Isabelia $\times$ pabstii foi baseada no typus, descrições do autor (Leinig 1971, 1976) e material vegetativo e frutificado coletado em campo.

\section{Resultados e Discussão}

Isabelia Barb.Rodr., Gen. Spec. Orchid. 1: 75. 1877. Typus: Isabelia virginalis Barb. Rodr., Gen. Spec. Orchid. 1: 76. 1877. Neolauchea Kraenzl., Bull. Herb. Boissier 5: 110. 1897. Sophronitella Schltr., Repert. Spec. Nov. Regni Veg. Beih. 35: 76. 1925. $\times$ Isanitella Leinig, Amer. Orchid Soc. Bull. 40: 710. 1971.

Erva epífita ou rupícola, simpodial. Raízes cilíndricas, originadas do rizoma, castanhas ou alvacentas. Rizoma cilíndrico, levemente achatado ou não, escandente ou não, prostrado ou pendente. Pseudobulbos heteroblásticos, oblongos ou obovados, lisos a enrugados, sulcados ou não, 1-2-foliados, dispostos de forma laxa ou congesta no rizoma, verdes a castanhos, protegidos por catafilos. Catáfilos orbiculares, amplexicaules, quando senis assemelham-se a fibras, fibras entrelaçadas ou não, alvacentos a castanho-claros. Folhas apicais, conduplicadas, oblongo-lanceoladas ou filiformes, coriáceas ou carnosas, verdes. Inflorescência terminal, 1-3-flora; pedúnculo inconspícuo ou não; brácteas do pedúnculo e florais lanceoladas, ampletivas. Flor calcarada; pedicelo inconspícuo ou não, verde; calcar ligado ao ovário, formado pela base das sépalas laterais e labelo, alvacento ou castanho a violáceo; sépalas lanceoladas com ápice agudo ou oblongas com ápice obtuso, róseas ou violáceas; pétalas lanceoladas com ápice agudo ou elípticas com ápice obtuso, alvas ou violáceas; labelo espatulado a lanceolado ou obovado, margem lisa, onduladacrenada a levemente crespa ou inconspicuamente crenulada, ápice agudo mucronado, retuso ou retuso apiculado, alvo ou violáceo, calo na base; calo inconspicuamente bilobado ou em par, alvo; coluna violácea ou alva e violácea, com alas ou não, quando presentes 2 , uma em cada lateral, na região da antera, violáceas; antera apical, violácea; polínias 8 , translucidas, azul-alvacentas ou amareladas; ovário e pedicelo verde a castanho. Fruto cápsula 3-locular, verde.

Através de estudos moleculares, as relações entre os táxons em Laeliinae estão sendo esclarecidas (van den Berg et al. 2000; van den Berg et al. 2009). 
Neolauchea Kraenzl. foi sinonimizado sob Isabelia por van den Berg \& Chase (2001), alegando que a mesma combinação realizada em 1968 por Senghas \& Teuscher era inválida por não seguir as normas do Código Internacional de Nomenclatura Botânica. Sophronitella Schltr. também foi sinonimizado sob Isabelia por van den Berg \& Chase (2001), sendo esta combinação suportada por dados moleculares, uma análise cladística, bem como pela existência de um hibrido natural entre I. pulchella e I. violacea. Consequentemente o nototáxon $I . \times$ pabstii também foi enquadrado sob Isabelia. Os táxons I. pulchella $\mathrm{f}$. alba Nunes ex Van den Berg \& M.W.Chase e I. violacea f. alba (Barb.Rodr.) F.Barros também foram combinadas (van den Berg \& Chase 2001; Barros 2003).

\section{Chave para as espécies de Isabelia}

1. Folhas filiformes, pedúnculo da inflorescência inconspícuo 3. I. virginalis

1'. Folhas oblongo-lanceoladas, pedúnculo da inflorescência $0,8-3,5 \mathrm{~cm}$ compr.

2. Pseudobulbos dispostos de forma laxa no rizoma; labelo com margem ondulada a crenada, ápice retuso; calcar ca. $4 \mathrm{~mm}$ compr. 1. I. pulchella

2'. Pseudobulbos dispostos de forma congesta no rizoma; labelo com margem lisa, ápice agudo, mucronado; calcar ca. 1-2 mm compr. 2. I. violacea

1. Isabelia pulchella (Kraenzl.) Van den Berg \& M.W.Chase, Lindleyana 16: 109. 2001. Basionimo: Neolauchea pulchella Kraenzl., Bull. Herb. Boissier 5: 110. 1897. Meiracyllium wettsteinii Porsch, Oesterr. Bot. Z. 55: 160. 1905. Isabelia pulchella (Kraenzl.) Senghas \& Teusch., Amer. Orchid Soc. Bull. 37: 502. 1968. nom. illeg. Isabelia pulchella var. alba Nunes, Bol. CAOB 3(3): 41. 1991. Isabelia pulchella f. alba Nunes ex Van den Berg \& M.W.Chase, Lindleyana 16: 109. 2001.

Figs. 2a-g, 3a-d, 4a

Erva epífita ou rupícola. Raízes ca. 0,6-9 × $0,1 \mathrm{~cm}$, castanhas ou alvacentas. Rizoma $10-112 \times$ $0,1-0,2 \mathrm{~cm}$, não achatado, escandente, prostrado ou pendente, $0,6-4 \mathrm{~cm}$ entre os pseudobulbos, ca. 2-3 nós entre os pseudobulbos. Pseudobulbos 4-14× 2-8 mm, obovados, lisos a enrugados, não sulcados, unifoliados, dispostos de forma laxa no rizoma, castanhos. Catáfilos envolvem os pseudobulbos ca. duas vezes o compr., fibras não entrelaçadas, castanho-claros. Folhas 1,4-10,5 × 0,1-0,3 cm, oblongo-lanceoladas, coriáceas. Inflorescência uniflora; pedúnculo 1,2-3,4 cm compr.; brácteas do pedúnculo ca. $2 \times 1 \mathrm{~mm}$; bráctea floral ca. $2 \times 1$ $\mathrm{mm}$. Flor violácea; pedicelo ca. $5 \times 1 \mathrm{~mm}$; calcar ca. $4 \times 2 \mathrm{~mm}$, castanho-violáceo; sépalas lanceoladas, ápice agudo; sépala dorsal 7-10 × 3-4 mm; sépalas laterais 7-9 × 3-4 mm; pétalas 8-12 × $2 \mathrm{~mm}$, lanceolada, ápice agudo; labelo 8-12 × 6-7 mm, obovado, margem ondulado-crenada a levemente crespa, ápice retuso; calo em par; coluna ca. $4 \times$ $3 \mathrm{~mm}$, violácea; alas da coluna ca. $1 \mathrm{~mm}$ compr., bastante delgadas; antera ca. $1 \times 1 \mathrm{~mm}$; polínias ca. $0,3 \mathrm{~mm}$ compr., translúcidas; ovário e pedicelo $11-12 \times 1 \mathrm{~mm}$, verde-escuros. Fruto ca. $14 \times 7 \mathrm{~mm}$. Material selecionado: Balsa Nova, Serra de São Luiz do Purunã, 12.VII.2004, fl., R.A. Kersten 898 (UPCB). Bocaiúva do Sul, Carijó, 16.VI.1953, fl., G. Hatschbach 3294 (HB, MBM); Serra S'Ana, 6.VII.1971, fl., G. Hatschbach 26834 (MBM). Carambeí, Catanduva de Fora, 26.V.2008, fl., M.E. Engels 6 (HUPG). Contenda, 12.VIII.2004, fl., R. Kersten 906 (UPCB). Curitiba, VI.1944, fl., A. Guimarães s.n. (RB 53198); Bariguí, Santa Felicidade, 15.V.1958, fl., M.G. Leinig 33 (HB); Parque Bariguí, V.1996, fl., V.A.O. Dittrich et al. s.n. (UPCB 27434). Jaguariaíva, Parque Estadual do Vale do Codó, 5.X.2011, fr., M.E. Engels 295 (HUPG). Mandirituba, Colônia Parque Verde, VII.1971, fl., L.T. Dombrowski \& Y.S. Kuniyoshi 2794 (HB). Mauá da Serra, 2009, fl., M.A. Guttiere 10 (HUEM). Pinhais, 26.VII.2005, fr., R. Kersten 1073 (EFC). Piraquara, 25.VI.1944, fl., G. Hatschbach 106 (MBM). Ponta Gossa, Balneário São Jorge, 21.VI.2011, fl., M.E. Engels et al. 274 (HUPG); Cachoeira da Mariquinha, 18.V.2011, fl., M.E. Engels et al. 275 (HUPG); Fazenda escola da Universidade Estadual de Ponta Grossa, 24.VI.1994, fl., R. Kaczmarech 438 (HUPG); Parque Estadual de Vila Velha, 7.VII.2011, fl. e fr., M.E. Engels 281 (HUPG). Porto Amazonas, Rio Iguaçú, 7.VI.1977, fl., G. Hatschbach 39979 (MBM). São José dos Pinhais, Guatupê, 29.V.1987, fl., J. Cordeiro \& J.M. Silva 437 (MBM, UPCB). São Mateus do Sul, Tezoura, 25.VI.1969, fl., G. Hatschbach \& C. kozicki 21668 (HB, MBM). Tibagí, Ilha Bowman, 8.IX.2006, fr., A. Bonnet 71280 (UPCB); Parque Estadual do Guartelá, 12.VII.2011, fl. e fr., M.E. Engels 284 (HUPG). Tijucas do Sul, Represa de Vossoroca, 25.VII.1988, fl., R. Kummrow 3035 (MBM, UPCB). 


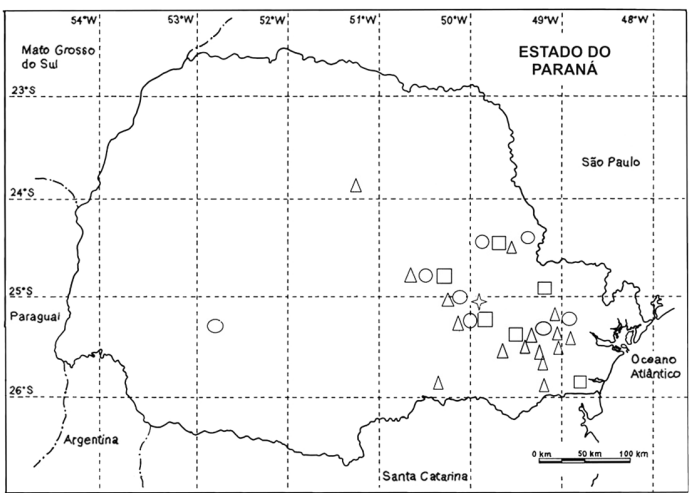

Figura 1 - Mapa de distribuição geográfica de Isabelia no estado do Paraná (mapa modificado de IPARDES 2011). ( $\triangle=$ I. pulchella; $\square=I$. violacea; $\bigcirc=I$. virginalis; $\diamond=$ Isabelia $\times$ pabstii $)$.

Figure 1 - Geographic distribution map of Isabelia in Parana State (map modifield of IPARDES 2011). ( $\triangle=$ I. pulchella; $\square=I$. violacea $; \mathrm{O}=$ I. virginalis; $\diamond=$ Isabelia $\times$ pabstii $)$.

I. pulchella é endêmica do Brasil (São Paulo, Rio de Janeiro, Paraná, Santa Catarina e Rio Grande do Sul), ocorrendo no domínio fitogeográfico da Mata Atlântica (Barros et al. 2012). No Paraná foram coletados 26 espécimes, em 16 municípios (Fig. 1), na Floresta Ombrófila Mista.

Segundo os critérios da IUCN (2010), I. pulchella se enquadra na categoria pouco preocupante (LC), pois a espécie é amplamente distribuída, ocorrendo em grande número de localidades, não sendo uma espécie ameaçada.

Isabelia pulchela diferencia-se das demais espécies por possuir rizoma escandente com disposição laxa dos pseudobulbos, labelo com margem ondulada-crenada a levemente crespa, com ápice retuso. Ocorre como epífita ou rupícola, em capões, floresta contínua, de galeria e ripárias, podendo formar densas touceiras. Corresponde a espécie mais comum no estado. Geralmente exibe uma competição por espaço acarretando o desenvolvimento pendente de frentes de crescimento (Fig. 3c). É considerada por Bonnet et al. (2011) como epífita indicadora de boa qualidade ambiental, por ser encontrada em áreas ripárias mais bem conservadas. Esta espécie é tanto simpátrica quanto sincrônica com I. violacea e I. virginalis. Coletada com flores no Paraná entre os meses de maio a julho. Maturação dos frutos com deiscência das sementes no início de outubro.
2. Isabelia violacea (Lindl.) Van den Berg \& M.W.Chase, Lindleyana 16: 109. 2001. Basionimo: Sophronitis violacea Lindl., Edwards's Bot. Reg. 26(Misc.): 18. 1840. Sophronia violacea (Lindl.) Kuntze, Revis. Gen. P1. 2: 681. 1891. Sophronitella violacea (Lindl.) Schltr., Repert. Spec. Nov. Regni Veg. Beih. 35: 76. 1925. Sophronitis violacea var. alba Barb.Rodr., Gen. Spec. Orchid. 2: 160. 1882. Isabelia violacea f. alba (Barb.Rodr.) F.Barros, Hoehnea 30: 182. 2003. Figs. 2h-o, 3e-h, 4b Erva epífita ou rupícola. Raízes $17-155 \times$ 0,5-2 mm, castanhas ou alvacentes. Rizoma ca. 2 mm de espessura, não achatado, não escandente, prostrado, 5-10 $\mathrm{mm}$ entre pseudobulbos, ca. 1 nó entre os pseudobulbos. Pseudobulbos 12-32 × 2-12 $\mathrm{mm}$, oblongos, lisos, sulcados, unifoliados, dispersos de forma congesta no rizoma, verdes a castanhos. Catáfilos envolvem os pseudobulbos, estes com mesmo comp., fibras não entrelaçadas, alvacentos a castanho-claros. Folhas 1,8-7,9 × 0,2-0,6 cm, oblonglo-lanceoladas, coriáceas. Inflorescência 1-3 flora; pedúnculo 0,8-3,5 cm compr; brácteas do pedúnculo ca. $5-10 \times 3-5 \mathrm{~mm}$; brácteas florais ca. 9-15 × 3-5 mm. Flor violácea; pedicelo ca. $15 \times 1$ mm; calcar ca. 1-2 mm compr., violáceo; sépalas lanceoladas, ápice agudo; sépala dorsal 7-23 $\times$ 2-6 mm; sépalas laterais 9-23 × 2-5,5 mm; pétalas 8-23 × 4-7 mm, lanceolada, ápice agudo; labelo 12-23 × 5-9 mm, espatulado a lanceolado, margem lisa, ápice agudo-mucronado, base alva; calo 1 , inconspicuamente bilobado; coluna ca. $5 \times 2-3 \mathrm{~mm}$, violácea mais escura que o perianto; alas da coluna, ca. $2 \times 1-15 \mathrm{~mm}$; antera ca. $1 \times 1 \mathrm{~mm}$; polínias ca. 0,3 $\times 0,1 \mathrm{~mm}$, azul-alvacentas; ovário e pedicelo 15-23 $\times$ 15-25 mm, castanho. Fruto 11-15 × 2-6 mm.

Material selecionado: Campo Largo, Serra S'Ana, 29.VI.1966, fl., G. Hatschbach 14512 (MBM). Cerro Azul, Morro Grande, VI.1957, fl., G. Hatschbach 4120 (HB, MBM). Guaratuba, Divisa, 3.VIII.1969, fl., G. Hatschbach 22083 (MBM). Jaguariaíva, Parque Estadual do Cerrado, 5.X.2011, fr., M.E. Engels 297 (HUPG). Ponta Grossa, Parque Estadual de Vila Velha, 7.VII.2011, fl. e fr., M.E. Engels 280 (HUPG). Tibagí, Parque Estadual do Guartelá, 1.VIII.2011, fl., M.E. Engels 286 (HUPG).

I. violacea é endêmica do Brasil (Bahia, Goiás, Distrito Federal, Minas Gerais, São Paulo, Rio de Janeiro, Paraná, Santa Catarina, Rio Grande do Sul), ocorrendo nos domínios fitogeográficos Mata Atlântica e Cerrado (Barros et al. 2012). No Paraná foram coletados 13 espécimes, em seis municípios (Fig. 1), em Cerrado e Mata Atlântica (Floresta Ombrófila Densa e Floresta Ombrófila Mista). 


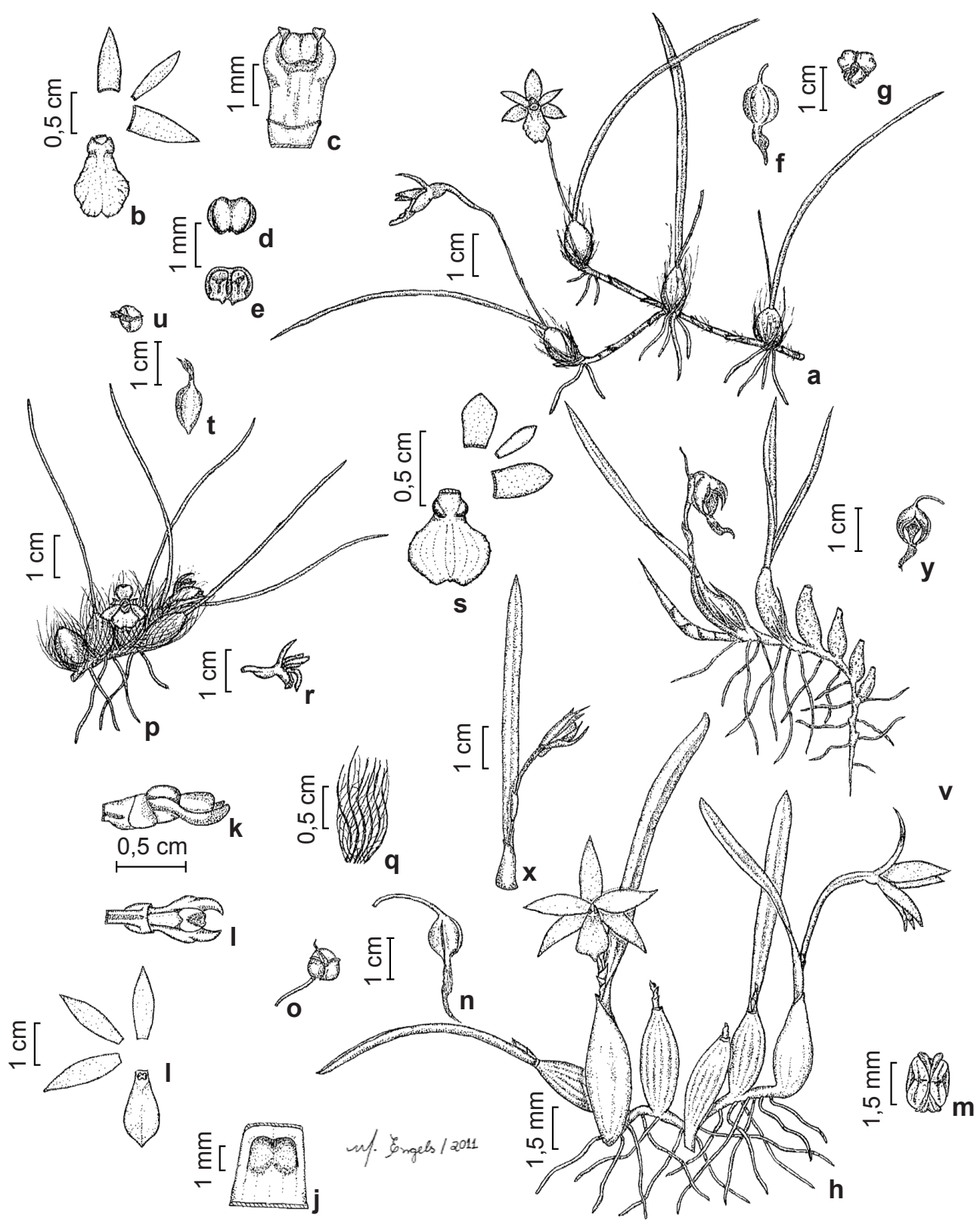

Figura 2 - Táxons de Isabelia encontrados no Paraná - a-g. Isabelia pulchella (M.E. Engels 006) - a. hábito; b. verticilos florais, de cima para baixo: sépala dorsal, pétala, sépala lateral, labelo; c. coluna, vista ventral; d-e. antera, vista dorsal e ventral, respectivamente; f-g. fruto, vista lateral e dorsal, respectivamente. h-o. Isabelia violacea (M.E. Engels \& W.S. Mancinelli 182) - h. hábito; i. verticilos florais, de cima para baixo: sépala dorsal, pétala, sépala lateral, labelo; j. base do labelo, evidenciando calos; k-1. coluna, vista lateral e dorsal, respectivamente; m. antera, vista ventral; n-o. fruto, vista lateral e dorsal, respectivamente. p-u. Isabelia virginalis (M.E. Engels 011) - p. hábito; q. bráctea do pseudobulbo; r. flor, vista lateral; s. verticilos florais, de cima para baixo: sépala dorsal, pétala, sépala lateral, labelo; t-u. fruto, vista lateral e dorsal, respectivamente. v-y. Isabelia x pabstii (M. Leinig HB 57196; M.E. Engels 294) - v-x. hábito; y. fruto, vista lateral. Figure 2 - Taxa of Isabelia found in Parana State. a-g. Isabelia pulchella (M.E. Engels 006) - a. habit; b. floral verticils, up-down: dorsal sepal, petal, lateral sepal, label; c. colunn, ventral view; d-e. anter, frontal and dorsal view, respectively; f-g. fruit, lateral and dorsal view, respectively. h-o. Isabelia violacea (M.E. Engels \& W.S. Mancinelli 182) - h. habit; i. floral verticils, up-down: dorsal sepal, petal, lateral sepal and label; j. label basis with callus in evidation; $\mathrm{k}-1$. collun, lateral and dorsal view, resptively. p-u. Isabelia virginalis (M.E. Engels 011) - p. habit; q. pseudobulbs bract; r. flower, lateral view; s. floral verticils, up-down dorsal sepal, petal, lateral petal, label; t-u. fruit, lateral and dorsal view respectively. v-y. Isabelia x pabstii (M. Leinig HB 57196; M.E. Engels 294) - v-x. habit; y. fruit, lateral vision. 

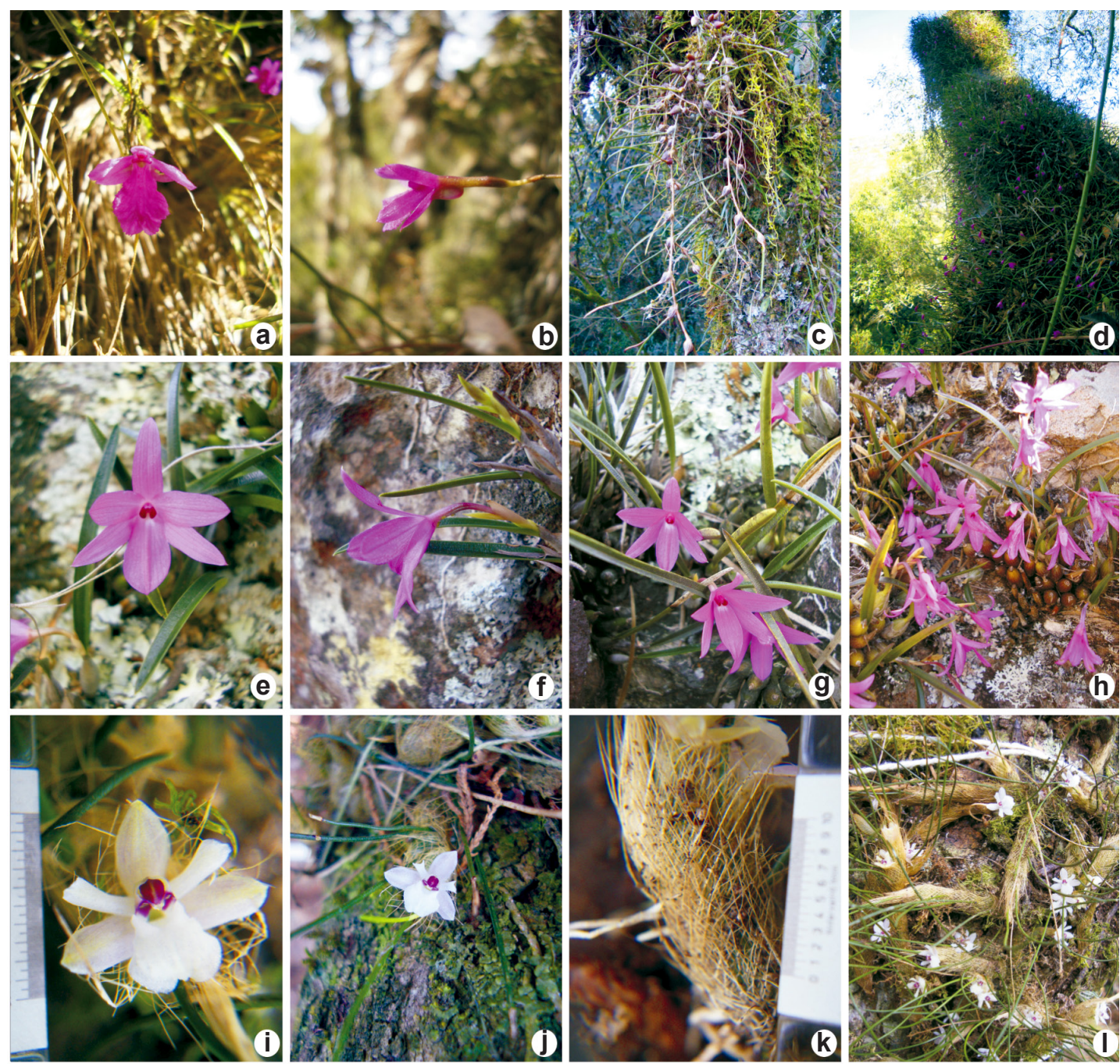

d)
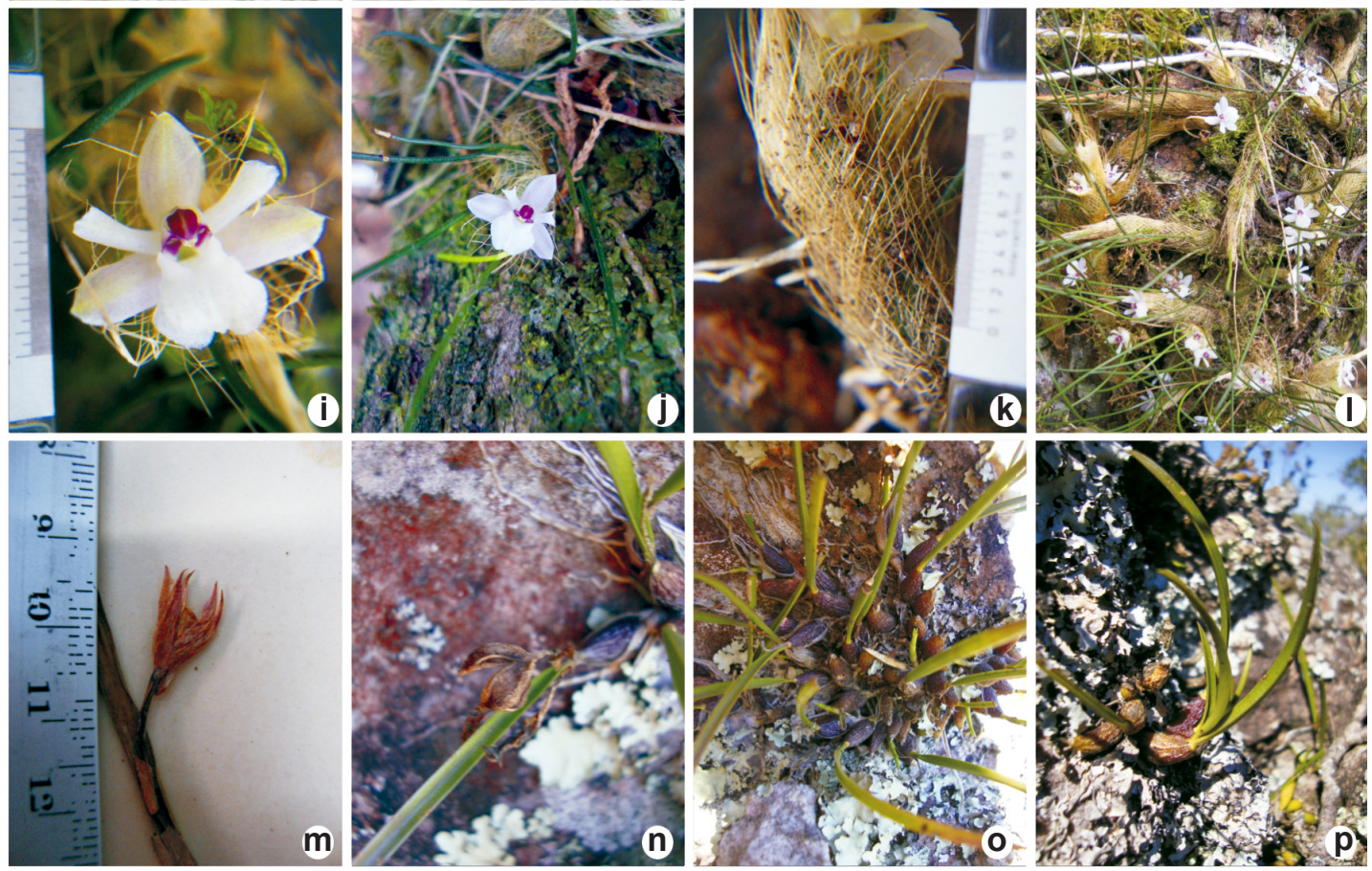

Figura 3 - a-d. Isabelia pulchella - a. flor, vista frontal; b. flor, vista lateral; c. hábito, evidenciando rizoma escandente e frente de crescimento pendente; d. hábito. e-h. Isabelia violacea - e. flor, vista frontal; f. flor, vista lateral; g-h. hábito. $\mathrm{i}-1$. Isabelia virginalis - i. flor, evidenciando morfologia dos verticilos florais; j. flores, vista geral; $\mathrm{k}$. brácteas dos pseudobulbos; 1. hábito. m-p. Isabelia × pabstii - m. flor (M. Leinig HB 57196); n. hábito, forma de vida rupícola em arenito, evidenciando fruto cenil; o-p. hábito, forma de vida rupícola em arenito.

Figure 3 - a-d. Isabelia pulchella - a. flower, frontal view; b. flower, lateral view; c. habit, in evidence (escantente) rizom and pending growth; d. habit. e-h. Isabelia violacea - e. flower, frontal view; $\mathrm{g}-\mathrm{h}$. habit. i-l. Isabelia virginalis - i. flower, in evidence the verticils morphology; $\mathrm{j}$. flowers general view; $\mathrm{k}$. pseudobubals bracts; 1 . habit. $\mathrm{m}$-p. Isabelia $\times$ pabstii $-\mathrm{m}$. flower; $\mathrm{n}$. habit, rupicol life form in arenitics rocks, in evidence the old fruit; o-p. habit, rupicol life form in arenitics rocks. 


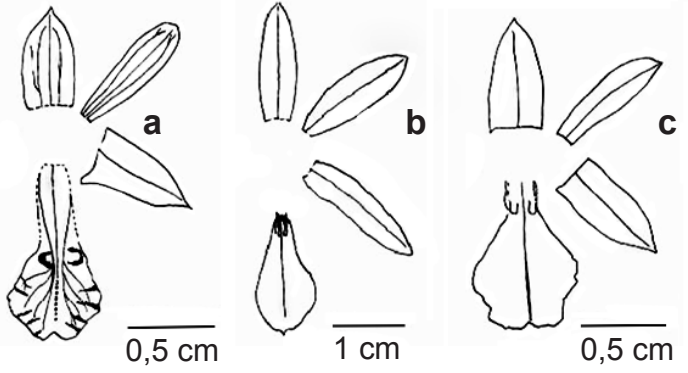

Figura 4-Comparação da morfologia floral entre Isabelia $\times$ pabstii e seus parentais - a. I. pulchella. b. I. violacea. c. Isabelia $\times$ pabstii. (modificado de Pabst \& Dungs 1975). Figure 4-Comparation of flower morphology between Isabelia pabstii and its parental -a. I. pulchella. b. I. violacea . c. I. pabstii (modified of Pabst \& Dungs 1975).

Encontrada em abundância no Parque Estadual de Vila Velha, Ponta Grossa, nas formações areníticas e na associação dos relictos de Cerrado com capões de Floresta com Araucária.

Isabelia violacea, segundo os critérios da IUCN (2010), se enquadra na categoria pouco preocupante (LC), pois a espécie é amplamente distribuída, ocorrendo em grande número de localidades, não sendo uma espécie ameaçada.

Isabelia violacea diferenciando-se das demais espécies por possuir pseudobulbos sulcados e possuir o ápice do labelo agudo-mucronado. Ao contrário de I. pulchella e I. virginalis, sua inflorescência não é exclusivamente uniflora. Ocorre como epífita ou rupícola em floresta de galeria, mata ripária e afloramentos rochosos, em locais bem iluminados. Esta espécie é simpátrica com I. pulchella e I. virginalis, sendo sincrônica com I. pulchella. Coletada com flores no Paraná entre julho a agosto. Maturação dos frutos com dispersão das sementes no início de outubro.

3. Isabelia virginalis Barb.Rodr., Gen. Spec. Orchid. 1: 76. 1877. Tipo: BRASIL. MINAS GERAIS: Caldas, 30.IV.1877, J. Barbosa Rodrigues s.n. (perdido). Lectotypus (aqui designado): ilustração original de Barbosa Rodrigues, de sua obra "Iconographie des Orchideés du Brésil 6 tab. 270", depositado na biblioteca do Jardim Botânico do Rio de Janeiro e reproduzido por Sprunger et al. (1996, v.1, t.398). Figs. 2p-u, 3i-1

Erva epífita ou rupícola. Raízes 5-80 × 0,5-1 $\mathrm{mm}$, alvacentas. Rizoma 1-2 mm de espessura, levemente achatado, não escandente, prostrado, ca. $5 \mathrm{~mm}$ entre os pseudobulbos, ca. 1-2 nós entre os pseudobulbos. Pseudobulbos 3-11 × 2-7 $\mathrm{mm}$, obovados, lisos a levemente enrugados, não sulcados, unifoliados, dispostos de forma congesta no rizoma, verdes a castanhos. Catáfilos envolvem os pseudobulbos ca. 1 vez e meia o seu compr., fibras entrelaçadas, castanho-claros. Folhas 14-78 × 0,5-1 $\mathrm{mm}$, filiformes, carnosas. Inflorescência uniflora; pedúnculo inconspícuo; bráctea do pedúnculo ca. 1-2 mm compr.; bráctea floral $1 \mathrm{ca}$. 2-5 mm compr. Flor róseo-clara e alva; pedicelo inconspícuo; calcar 2-2,5 × 1-2 mm, alvacente; sépalas lanceoladas, ápice agudo, róseo-claras; sépala dorsal 5-7 × 3-4 $\mathrm{mm}$; sépalas laterais 6-7 $63 \mathrm{~mm}$; pétalas $5-6 \times$ 1-1,5 mm, lanceoladas, ápice agudo, alvas; labelo 5-6 × 5-6 mm, obovado, margem inconspicuamente crenulada, ápice retuso, apiculado, alvo; calos em par; coluna ca. $3 \times 2 \mathrm{~mm}$, alva e violácea, alas ausentes; antera ca. $1 \mathrm{~mm}$ compr.; polínias ca. 5 $\times 2,5 \mathrm{~mm}$, amareladas; ovário e pedicelo $2-5 \mathrm{~mm}$ compr., verdes. Fruto ca. $12 \times 5 \mathrm{~mm}$.

Material selecionado: Campina Grande do Sul, Sítio do Belizário, 3.VIII.1967, veg., G. Hatschbach 16879 (MBM). Carambeí, Catanduva de Fora, 24.V.2011, fl., M.E. Engels 277 (HUPG). Curitiba, Capão da Imbuia, 6.II.1968, fl., Y.S. Kuniyoshi \& L.T. Dombrowski (MBM 250489). Jaguariaíva, Parque Estadual do Cerrado, 27.V.1997, fl., A.C. Cervi et al. 6286 (UPCB). Ponta Grossa, Parque Estadual de Vila Velha, 29.V.1951, fl., G. Hatschbach 2266 (MBM, SP). Quedas do Iguaçú, Rio das Cobras, 14.VI.1999, fl., J. Carneiro 694 (MBM). Sengés, Morro Pelado, 16.VI.1971, fl., G. Hatschbach 26772 (MBM). Tibagí, Parque Estadual do Guartelá, 16.V.2011, fl., M.E. Engels \& W.S. Mancinelli 276 (HUPG).

I. virginalis ocorre na Argentina (Misiones) e no Brasil (Minas Gerais, São Paulo, Rio de Janeiro, Paraná) no domínio fitogeográfico da Mata Atlântica (Govaerts 2011; Barros et al. 2012). No Paraná foram coletados 13 espécimes, em oito municípios (Fig. 1), em Floresta Ombrófila Mista e Floresta Estacional Semidecidual.

De acordo com Hatschbach \& Ziller (1995), I. virginalis está em perigo de extinção no estado do Paraná. Contudo, segundo os critérios da IUCN (2010), se enquadra na categoria pouco preocupante (LC), pois a espécie é amplamente distribuída, ocorrendo em grande número de localidades, não sendo uma espécie ameaçada.

Isabelia virginalis pode ser identificada facilmente pela morfologia vegetativa devido a suas folhas filiformes e catafilos semelhantes a fibras entrelaçadas. Também pode ser diferenciada das demais espécies pelo pedúnculo inconspícuo, 
flores róseo-claras com labelo alvo, este com ápice retuso e apiculado. Segundo Rodrigues (1877), esta espécie é bastante diferenciada pela presença das brácteas fibrosas e reticuladas que cobrem os pseudobulbos e que após a queda das folhas lhe dão o aspecto de "lagartas peludas" (Fig. 3k). Ocorre como epífita e rupícola em capões, matas ripárias e de galeria, em locais bem iluminados, normalmente no estrato superior e nas bordas. É considerada por Bonnet et al. (2011) como epífita indicadora de boa qualidade ambiental, devido a ser encontrada em áreas ripárias mais bem conservadas. Esta espécie é simpátrica com I. pulchella e I. violacea, sendo sincrônica com I. pulchella. Coletada com flores no Paraná de maio a junho. Maturação dos frutos com deiscência das sementes no início de outubro, sendo que os frutos caem logo em seguida.

4. Isabelia $\times$ pabstii (Leinig) Van den Berg \& M.W.Chase, Lindleyana 16: 109. 2001. Typus: BRASIL. PARANÁ: Ponta Grossa, Vila Velha, VI.1970, M. Leinig (Holotypus HB 57196!). Basionimo: $\times$ Isanitella pabstii Leinig, Bradea 2: 63. 1976.

Figs. 2v-x, 3m-p, $4 \mathrm{c}$

Erva rupícola. Raízes $10-80 \times 0,5-1 \mathrm{~mm}$, alvacentas. Rizoma 1-2 mm de espessura, não achatado, não escandente, prostrado, 3-12 mm compr. entre os pseudobulbos, ca. 2 nós entre pseudobulbos. Pseudobulbos 8-25 × 3-7 mm, fusiforme-oblongos, enrugados, não sulcados, 1-2-foliados, dispersos de forma congesta no rizoma, verdes a castanhos. Catáfilos envolvem os pseudobulbos, estes com mesmo comp., fibras não entrelaçadas, castanho-claros. Folhas 2,5-14 $\times 0,1-0,5 \mathrm{~cm}$, oblongo-lanceoladas, coriáceas. Inflorescência 1-2-flora; pedúnculo 0,7-2,5 cm compr.; brácteas do pedúnculo ca. 2 × $5 \mathrm{~mm}$; brácteas florais ca. $2 \times 6 \mathrm{~mm}$. Flor róseo-violácea; pedicelo ca. $6 \times 1 \mathrm{~mm}$ compr.; calcar $1-3 \times 1 \mathrm{~mm}$, róseo-violáceo; sépalas oblongas, ápice obtuso; sépala dorsal $6,5-13 \times 5,5 \mathrm{~mm}$; sépalas laterais $6,5-13 \times 5,5 \mathrm{~mm}$; pétalas $7-13 \times 2 \mathrm{~mm}$, elípticas, ápice obtuso; labelo ca. $9 \times 6 \mathrm{~mm}$, obovado, margem ondulada-crenada, ápice retuso; calos em par; coluna violácea, alas presentes; polínias não observadas; ovário e pedicelo 1,5-2 × 0,1 cm. Fruto ca. $10 \times 7 \mathrm{~mm}$.

Material examinado: BRASIL. PARANÁ: Ponta Grossa, Parque Estadual de Vila Velha, VI.1970, fl., M. Leinig (HB 57196); 30.IX.2011, fr., M.E. Engels 294 (HUPG).

Ocorre sobre os arenitos do Parque Estadual de Vila Velha (P.E.V.V.), Ponta Grossa, Paraná (Fig. 1).
Isabelia $\times$ pabstii, segundo os critérios da IUCN (2010), se enquadra na categoria perigo crítico (CR), ocorrendo em apenas uma localidade no estado do Paraná (D1).

Isabelia $\times$ pabstii é hibrido natural entre I. pulchella e I. violacea coletado por Leinig em 1969 no P.E.V.V. Deste período até o atual não havia registro de novas coletas deste nototáxon. No entanto, nas expedições realizadas ao P.E.V.V., foram encontradas colônias de Isabelia $\times$ pabstii vegetando sobre arenitos em áreas bastante ensolaradas (Fig. $3 n-p)$. Este nototáxon possui forma intermediária entre seus parentais: pseudobulbos com o tamanho assemelhado aos de I. violacea, contudo não sulcados e sim enrugados, como em I. pulchella; os pseudobulbos podem apresentar duas folhas (Fig. 3 p), o que não é observado em nenhuma das espécies parentais; as folhas possuem tamanho intermediário aos dos parentais; o rizoma não escandente se assemelha ao de I. violacea; o fruto é semelhante ao dos parentais (Fig. 3n), contudo, o pedicelo possui aproximadamente o mesmo comprimento que o fruto, como em I. pulchella. De acordo com Leinig (1971) o calcar, a coluna e o labelo possuem formas intermediárias entre os parentais e as pétalas e sépalas possuem maior semelhança com I. pulchella (Fig. 4a), floresce em junho.

\section{Agradecimentos}

Ao Instituto Ambiental do Paraná por conceder a licença de coleta para as unidades de conservação no Paraná. A Pró-reitoria de extensão da Universidade estadual de Ponta Grossa por disponibilizar motorista e transporte para realização das expedições botânicas. À Fundação Araucária a bolsa concedida. Aos examinadores M.Sc. Anna Luiza P. Andrade, Dr. Eric C. Smidt, Dr. Ivana F. Barbola e M.Sc. Melissa K.F.S. Nogueira a participação na banca do trabalho de conclusão de curso do primeiro autor, e pelas valiosas contribuições. Aos curadores dos herbários EFC, HB, HUEM, HUPG, MBM, RB, SP e UPCB a hospitalidade e por disponibilizar as coleções para estudo.

\section{Referências}

Barros, F. 2003. Notas taxonômicas sobre espécies brasileiras dos gêneros Catasetum, Isabelia, Veyretia, Acianthera e Anathallis (Orchidaceae). Hoehnea 30: 181-191.

Barros, F.; Vinhos, F.; Rodrigues, V.T.; Barberena, F.F.V.A. \& Fraga, C.N. 2012. Orchidaceae. In: Lista de espécies da flora do Brasil. Jardim Botânico do Rio 
de Janeiro. Disponivel em $<$ http.//floradobrasil.jbrj. gov.br/2012/FB011761>. Acesso em 16 Set 2012.

Bonnet, A.; Curcio, G.R.; Lavoranti, O.J. \& Galvão, F. 2011. Flora epífita vascular em três unidades vegetacionais do rio Tibagi, Paraná, Brasil. Rodriguésia 62: 491-498.

Fidalgo, O. \& Bononi, V.L.R. 1989. Técnicas de coleta, preservação e herborização de material botânico. Reimpressão. Instituto de Botânica de São Paulo, São Paulo. 62p.

Gonçalves, E.G. \& Lorenzi, H. 2011. Morfologia vegetal: organografia e dicionário ilustrado de morfologia das plantas vasculares. $2^{a}$ ed. Instituto Plantarum de Estudos da Flora, São Paulo. 512p.

Govaerts, R. In: Royal Botanical Garden. Disponível em $<$ http.//www.kew.org/wcsp/monocots $>$. Acesso em 1 Ago 2011.

Hatschbach, G.G. \& Ziller, S.R. 1995. Lista vermelha de plantas ameaçadas de extinção no estado do Paraná. SEMA/GTZ, Curitiba. 139p.

IPARDES - Instituto Paranaense de Desenvolvimento Econômico e Social. Disponível em <http:// http:// www.ipardes.gov.br/index.php?pg_conteudo $=1 \&$ cod conteudo=25>. Acesso em 28 Dez 2011.

IUCN. Standards and Petitions Working Group. 2010. Guidelines for Using the IUCN Red List Categories and Criteria. Versão 8.1. Disponível em <http:// intranet.iucn.org/webfiles/doc/SSC/RedList/ RedListGuidelines.pdf>. Acesso em 3 Out 2011.

Joppa, L.N.; Roberts, D.L. \& Pimm, S.L. 2010. How many species of flowering plants are there? Proceedings of the Royal Society. Disponível em $<$ http://rspb.royalsocietypublishing.org $>$. Acesso em 15 Jul 2010.

Leinig, M. 1971. Isanitella - a new intergeneric hybrid. American Orchid Society Bulletin 40: 709-712.

Leinig, M. 1976. Validation of Ornithocidium roczonii and Isanitella pabstii. Bradea 2: 62-63.
Pabst, G.F.J. \& Dungs, F. 1975. Orchidaceae Brasilienses I. Brucke-Verlag Kurt Schmersow, Hildesheim. 408p.

Pridgeon, A.M.; Cribb, P.J.; Chase, M.W. \& Rasmussen, F.N. 2005. Genera Orchidacearum IV. Epidendroideae I. Oxford Univesity Press, New York. 672p.

Rodrigues, J.B. 1877. Genera et Species Orchidearum Novarum I. Imprimerie de C. et. H. Fleiuss, Rio de Janeiro. 295p.

Sprunger S.; Cribb, P. \& Toscano de Brito, A.L.V. 1996. João Barbosa Rodrigues Iconographie des Orchidées du Brésil. v.1: The illustrations. Friedrich Reinhardt Verlag, Basle. 540p.

Thiers, B. Index Herbariorum. Part I: The herbaria of the world. New York Botanical Garden. Disponível em $<$ http://sweetgum.nybg.org/ih/>.Acesso em 16 Set 2012.

Van den Berg, C.; Higgins, W.E.; Dressler, R.L.; Whitten, W.M.; Soto Arenas, M.A.; Culham, A. \& Chase, M.W. 2000. A phylogenetic analysis of Laeliinae (Orchidaceae) based on sequence data from internal transcribed spacers (ITS) of nuclear ribosomal DNA. Lindleyana 15: 96-114.

van den Berg, C. \& Chase, M.W. 2001. Nomenclatural notes on Laeliinae - II. Additional combinations and notes. Lindleyana 16: 109-112.

van den Berg, C.; Higgins, W.E.; Dressler, R.L.; Whitten, W.M.; Soto-Arenas, M.A. \& Chase, M.W. 2009. Phylogenetic study of Laeliinae (Orchidaceae) based on combined nuclear and plastid DNA sequences. Annals of Botany 104: 417-430.

Veloso, H.P.; Rangel Filho, A.L.R. \& Lima, J.C.A. 1991. Classificação da vegetação brasileira adaptada a um sistema universal. Instituto Brasileiro de Geografia e Estatística, Estatística/Projeto Radam Brasil, Rio de Janeiro. 123p.

Vidal, W.N. \& Vidal, M.R.R. 1972. Botânica-organografia: quadros sinópticos ilustrados de fanerógamas. Editora da Universidade Federal de Viçosa, Viçosa. 118p. 